\title{
USO DE MATERIAIS ALTERNATIVOS EM CAMADAS DE PAVIMENTOS ASFÁLTICOS: UMA ANÁLISE BIBLIOGRÁFICA
}

\section{ARTIGO ORIGINAL}

SILVA, Marcos Vinicius Dias da ${ }^{1}$, SANTOS, Rafaella Oliveira Guimarães ${ }^{2}$

SILVA, Marcos Vinicius Dias da. SANTOS, Rafaella Oliveira Guimarães. Uso de materiais alternativos em camadas de pavimentos asfálticos: uma análise bibliográfica. Revista Científica Multidisciplinar Núcleo do Conhecimento. Ano 06, Ed. 05, Vol. 06, pp. 67-82. Maio de 2021. ISSN: 2448-0959, Link de acesso: https://www.nucleodoconhecimento.com.br/engenharia-civil/camadas-de-

pavimentos, $\quad$ DOI: 10.32749/nucleodoconhecimento.com.br/engenhariacivil/camadas-de-pavimentos

\section{RESUMO}

A importância que as rodovias têm para a economia brasileira é indiscutível, porquanto elas são os principais meios de transporte utilizados no país. Todavia, no Brasil, ainda há uma quantidade significante de rodovias não pavimentadas; um dos empecilhos que podem justificar a não realização deste tipo de obra é a questão econômica. Além disso, o fato de a maioria dos materiais tradicionais utilizados na pavimentação não serem renováveis dificulta ainda mais a solução deste dilema. Sendo assim, é cada vez mais frequente pesquisas com materiais denominados alternativos que podem ser aplicados em camadas de pavimentos asfálticos e que respeitem a todos os requisitos normativos. Logo, esta pesquisa teve como propósito analisar, através de pesquisas bibliográficas, a viabilidade de uso de alguns materiais alternativos para estabilização de solos visando aplicação em

\footnotetext{
1 Graduação.

2 Mestre.
}

RC: 84863

Disponível em: https://www.nucleodoconhecimento.com.br/engenharia-civil/camadas-depavimentos 
camadas de pavimento asfáltico; mais especificamente foi analisado parâmetros de resistência como CBR e expansão dos trabalhos estudados. Os materiais selecionados foram: solo brita, RCD, chamote cerâmico, aço-brita, escória de aciaria, pó de brita, cerâmica vermelha e cinza da casa de arroz e cal. Através dos resultados percebe-se que geralmente nas misturas que usam os materiais alternativos finos a quantidade de solo tende a ser maior que nas misturas com os materiais alternativos granulares e que a cal pode ser utilizada em misturas a fim de melhorar a resistência da mesma. Enfim, notou-se que a maioria dos materiais alternativos, com exceção do pó de brita, mostrou viabilidade para ser aplicados em bases e sub-bases de pavimentos.

Palavras-chave: Pavimentação, Ensaios Laboratoriais, Viabilidade.

\section{INTRODUÇÃO}

As rodovias são os principais meios de transportes utilizados no Brasil, de acordo com a Confederação Nacional do Transporte (CNT, 2019). Elas são fundamentais para a economia do país, são responsáveis pelo deslocamento de cargas e pessoas no território brasileiro e, além disso, faz ligações com outras nações. Entretanto, uma quantidade significante de trecho da malha rodoviária no país, cerca de $78,55 \%$, ainda não está pavimentada. Isso gera um certo desconforto e coloca o Brasil em uma posição indesejada em relação ao ranking dos países que mais investem em pavimentação no mundo. Países como Uruguai, Argentina e Equador os quais possuem extensão territorial inferior à do Brasil apresentam maior densidade da malha rodoviária pavimentada. Um dos fatores que podem justificar a resistência na realização de obras de pavimentação no Brasil é a questão econômica.

O Departamento Nacional de Infraestrutura de Transportes DNIT (2006), entende que o pavimento de uma rodovia consiste em um sistema cujo principal propósito é disponibilizar uma superfície de rolamento livre e desempenada e que permita a

RC: 84863

Disponível em: https://www.nucleodoconhecimento.com.br/engenharia-civil/camadas-depavimentos 
circulação de veículos de forma confortável, segura e econômica. Esse sistema é constituído por camadas finitas que são construídas sobre o subleito o qual é considerado teoricamente como infinito. De maneira geral, os pavimentos são divididos em três classes: rígidos, semirrígidos e flexíveis. Dentre estes, o mais usual no Brasil é o flexível por ser considerado o mais econômico.

Como os materiais tradicionais usados na pavimentação não são renováveis e representam um alto investimento na realização das obras, é imprescindível que se pesquise materiais alternativos para substituir aqueles. Assim, surgem estudos que garantem uma finalidade adequada a determinados materiais que antes não tinham uma função específica e, ao mesmo tempo, garante uma obra com preço mais acessível.

Nesse sentido, é cada vez mais frequente pesquisas com o intuito de encontrar materiais alternativos que tenham uso viável na construção de pavimentos rodoviários. Há vários estudos que apontam a viabilidade do uso de materiais tais como, resíduos sólidos de construção e demolição (RCD), cascas de grãos (como soja e arroz), cerâmica vermelha, aço-brita, escória de aciaria, entre outros.

Logo, a principal finalidade desse trabalho foi analisar, através de pesquisas bibliográficas, a viabilidade de uso de alguns materiais alternativos para estabilização de solos visando aplicação em camadas de pavimento asfáltico. Mais especificamente, objetivou-se analisar se a resistência mecânica, em termos dos parâmetros de CBR e expansão, que essas misturas apresentam permite empregálas em camadas de base e sub-base de pavimento. Pretende-se, dessa forma, examinar quais misturas, com suas respectivas dosagens, apresentaram resultados mais satisfatórios, que vão ao encontro dos requisitos normativos, isto é, que garanta um pavimento resistente, confortável, que, enfim, tenha viabilidade técnica. 


\section{METODOLOGIA}

O presente trabalho foi realizado por meio de pesquisas bibliográficas. Analisaramse obras de outros autores que estudaram a temática a fim de comparar os resultados encontrados. A priori, foram feitas buscas em plataformas como Google Acadêmico e Scielo com o intuito de verificar quais os trabalhos realizados na área até o momento, considerando os publicados a partir de 2016. Após, selecionou-se os trabalhos que mais se aproximam do objetivo da pesquisa. Além de revisão teórica, este trabalho também possui como características o fato de ser explicativo, descritivo e qualiquantitativo.

Como explicado por Gil (2008), a pesquisa explicativa tem o intuito de identificar quais fatores são responsáveis pela ocorrência dos fenômenos analisados e, o mais importante, busca o porquê de cada fato. No que diz respeito à pesquisa descritiva, esta, conforme Prodanov e Freitas (2013), visa descrever, analisar e verificar as relações entre os fatos e os fenômenos, aqui há uma análise detalhada a cerca de um determinado fato para melhor entendimento do mesmo.

Devido à necessidade de se apresentar os dados tanto de forma descritiva quanto numérica ou estatística (com o auxílio de tabelas e/ou gráficos), faz-se necessário adotar uma abordagem qualiquantitativa. Gerhardt e Silveira (2009) consideram este tipo de abordagem válida, pois se admite uma abordagem mais ampla. Para França (2015) na abordagem qualitativa o que existe é uma abordagem mais teórica, descritiva; já na abordagem quantitativa, o foco é a análise de dados numéricos e estatísticos.

Os trabalhos selecionados, os quais deixam evidente o uso promissor dos materiais alternativos, são especificados na Tabela 1. 
Tabela 1 - Trabalhos analisados

\begin{tabular}{|c|c|c|c|}
\hline Material & ID & Autores & Ano \\
\hline \multirow[t]{2}{*}{ Solo brita } & E1 & Costa e Pinto (2017) & 2017 \\
\hline & E2 & Zappe et al. (2017) & 2017 \\
\hline \multirow{3}{*}{$\begin{array}{l}\text { Resíduos de Construção Civil } \\
\text { (RCD) }\end{array}$} & E3 & Oliveira (2017) & 2017 \\
\hline & E4 & Santos et al. (2019) & 2019 \\
\hline & E5 & Zimmer e Omido (2019) & 2019 \\
\hline Chamote Cerâmico & E6 & Sales (2018) & 2018 \\
\hline Aço-brita & E7 & Macedo (2018) & 2018 \\
\hline \multirow[t]{2}{*}{ Escória de Aciaria } & E8 & Costa e Santos (2019) & 2019 \\
\hline & E9 & Carvalho (2017) & 2017 \\
\hline Pó de Brita & E10 & Sityá e Machado (2019) & 2019 \\
\hline Cerâmica Vermelha & E11 & Sousa et al. (2019) & 2019 \\
\hline \multirow[t]{2}{*}{ Cinza da Casca de Arroz e Cal } & E12 & Bonfante e Carpio (2016) & 2016 \\
\hline & E13 & Sousa e Belchior (2017) & 2017 \\
\hline
\end{tabular}

Fonte: Elaborado pelo autor.

No total foram treze trabalhos analisados; optou-se pelas pesquisas mais recentes, os materiais alternativos estudados foram: solo brita, RCD, chamote cerâmico, açobrita, escória de aciaria, pó de brita, cerâmica vermelha e cinza da casa de arroz e cal.

\section{REVISÃO TEÓRICA}

O pavimento de uma rodovia, de acordo como o entendimento do Departamento Nacional de Infraestrutura de Transportes (DNIT, 2006), é um sistema, também chamado de superestrutura, composto por diferentes camadas de espessuras finitas. Essas camadas são construídas sobre um espaço considerado teoricamente infinito (infraestrutura) o qual é conhecido como subleito. O propósito de um sistema RC: 84863

Disponível em: https://www.nucleodoconhecimento.com.br/engenharia-civil/camadas-depavimentos 
rodoviário é disponibilizar um plano ou uma superfície de rolamento livre e desempenada de tal maneira que garanta a circulação dos veículos de forma segura, confortável e econômica.

A estrutura do pavimento, feita sobre a terraplanagem, deve resistir aos esforços gerados pelo tráfego e os distribuir além de resistir aos desgastes gerados pelas alterações climáticas, frenagem, arrancada e peso em excesso. Para Senço (2008), há duas classificações para os pavimentos: rígidos e flexíveis. Os pavimentos rígidos são constituídos de concreto de cimento Portland, por isso, possuem deformabilidade mínima, quando sujeitos a deformações rompem por tração na flexão. Já os pavimentos flexíveis se deformam até um determinado ponto sem se romper.

Todavia, segundo o DNIT (2006), há uma outra classe de pavimento, os semirrígidos, cuja principal característica é o fato de ser composta por uma base cimentada através de aglutinantes com propriedades cimentícias, como por exemplo uma camada de solo cimento, envolvida por uma camada asfáltica.

\section{MATERIAIS ALTERNATIVOS}

Hoje em dia está em pauta discussões de medidas que visam amenizar os problemas envolvendo questões ambientais: poluição de diversos tipos, descarte inadequado de lixo, o aumento do uso de energias poluentes (incentivo ao uso de energias limpas) e extração de materiais não renováveis. Na pavimentação, o consumo de materiais encontra um grande empecilho: alguns não são renováveis. Diante disso, a utilização de materiais alternativos vem ganhando força, atraindo a atenção de pesquisadores, transformando-se, dessa forma, em uma alternativa viável para sanar o problema da escassez de matéria-prima além de dar uma destinação adequada aos diversos materiais que são gerados por diferentes atividades produtivas (ARAÚJO, 2008).

RC: 84863

Disponível em: https://www.nucleodoconhecimento.com.br/engenharia-civil/camadas-depavimentos 
Muitos materiais alternativos são objetos de estudo com o intuito de analisar a viabilidade dos mesmos serem utilizados em camadas de pavimentos flexíveis. Esses materiais variam desde os naturais aos oriundos de atividades antrópicas. De maneira geral, como requisitos normativos para verificação da viabilidade dos materiais, tomou-se os parâmetros especificados por DNIT (2006) para as amostras a serem utilizadas nas camadas da pavimentação, a saber:

Material para execução de reforço de subleito: CBR $\geq 12 \%$, expansão $\leq 1,0 \%$.

Material para execução de sub-base: CBR $\geq 20 \%$, expansão $\leq 1,0 \%$.

Material para execução de base de pavimento: CBR $\geq 80 \%$, expansão $\leq 0,5 \%$ e para caso de rodovias vicinais $C B R \geq 60 \%$, expansão $\leq 0,5 \%$.

\section{SOLO BRITA}

A mistura solo-brita é utilizada constantemente em bases de pavimentos por apresentar considerável estabilidade e durabilidade. Essa mistura alternativa desperta cada vez mais a atenção dos pesquisadores. Costa e Pinto (2017), por exemplo, estudaram a mistura de um solo tropical característico da região de Manaus (AM) com material britado. As misturas adotadas foram duas: 17\%solo + $30 \%$ areia $+53 \%$ brita e $35 \%$ solo $+25 \%$ areia $+40 \%$ brita; os ensaios, seis: granulometria, massa específica dos grãos, limites de consistência, compactação, expansão e CBR. Conquanto a primeira mistura também apresentou valores de CBR e expansão satisfatórios, a segunda mistura, com menor teor de brita, foi a que se mostrou mais viável porquanto apresentou CBR médio de 98,8\% e a expansão média de $0,042 \%$. Assim, ambas são indicadas tanto para base quanto para subbase de pavimentos.

Zappe et al. (2017) avaliaram a viabilidade técnica e econômica do uso do solo (argiloso laterítico) da região noroeste do estado do Rio Grande do Sul misturado

RC: 84863

Disponível em: https://www.nucleodoconhecimento.com.br/engenharia-civil/camadas-depavimentos 
com britas de basalto em bases e sub-bases de pavimentos. Para isso os ensaios de análise granulométrica por sedimentação, limite de liquidez, limite de plasticidade, compactação e CBR foram realizados. Além do solo puro analisou-se as seguintes misturas: $50 \%$ SLAD + 50\%BGS, $40 \%$ SLAD + 60\%BGS e $30 \%$ SLAD + 70\%BGS. As abreviaturas SLAD e BGS significam, respectivamente, Misturas de granulometria descontinua de solo laterítico com agregado graúdo e Brita Graduada Simples.

Em relação aos parâmetros que medem a resistência dos materiais observou-se que a mistura que apresentou melhores resultados de CBR foi a 40\%SLAD + 60\%BGS com $83,28 \%$ e expansão $0,07 \%$; o pior resultado foi o da mistura $30 \%$ SLAD + $70 \% B G S$, porém, os autores ressaltam que provavelmente ocorreu alguns problemas técnicos durante a execução dos ensaios o que pode justificar os resultados encontrados (CBR de 32,47\% e expansão de 0,3\%). Assim, conclui-se que a mistura com $60 \%$ de BGS é adequada para uso em base e sub-base de pavimentos de baixo volume de tráfego e as demais para base e sub-base de estacionamentos, apenas (ZAPPE et al., 2017).

\section{RESÍDUOS DE CONSTRUÇÃO CIVIL (RCD)}

Oliveira (2017), estudou a aplicação deresíduos de construção e demolição (RCD), derivados da construção civil, em camadas de base e sub-base de pavimentação na cidade de São Luís (MA). Como base nesses estudos foi constado que para a localidade estudada, para aquela composição de RCD, os resultados foram satisfatórios para serem utilizados em base (com 3\% ou 6\% de Cimento Portland ou cal) e para sub-base.

Com o mesmo intuito, só que agora para a pavimentação da Avenida Paulino Rocha, em Fortaleza (CE), Santos et al. (2019), realizou um trabalho onde foi analisado o comportamento dos materiais experimentais. Os ensaios realizados foram os seguintes: granulométricos, compactação, Índice de Suporte Califórnia (CBR), limite de liquidez (LL) e limite de plasticidade (LP). Os resultados de CBR 
encontrados foram satisfatórios, visto que os valores ficaram acima do mínimo necessário (80\%), variou entre $80,3 \%$ a $114,8 \%$; quanto aos valores de expansão estes também atenderam aos critérios estabelecidos pelo DNIT (2006), variaram de $0 \%$ a $0,2 \%$. Ou seja, tanto os resultados de expansão quanto os de CBR tornam as misturas adequadas para uso em base e sub-base de pavimentos flexíveis.

Tradicionalmente as camadas de base a sub-base de pavimentos são constituídas por materiais tradicionais (brita e pedrisco). Entretanto, a fim de analisar a eficácia de RCD, Zimmer e Omido (2019) estudaram a substituição dos materiais tradicionais pelo alternativo. Denominou-se dois traços o $A$ e o $B$, sendo o primeiro para os materiais convencionais e o segundo, para o alternativo. A mistura do traço B era de $10 \%, 10 \%$ e $80 \%$ respectivamente, de brita, pedrisco e solo; já a mistura do traço B era de $35 \%$ do RCC1, $40 \%$ do RCC2 e $25 \%$ do solo.

Realizou-se ensaios de granulometria, limite de liquidez, limite de plasticidade, índice de plasticidade, compactação e CBR. O solo utilizado na mistura RCC/SOLO foi coletado na Jazida Izaura localizada na cidade de Itaporã (MS). A média do CBR do traço A foi de 50,18\%; para o traço B encontrou-se CBR médio de 137,66\% e expansão média de 0,44\%. Logo, notou que a utilização RCC1 e RCC2 trouxe melhoria ao solo principalmente em relação ao valor de CBR (aumento de 254,33\%). A mistura atende aos requisitos mínimos estabelecidos, portanto é indicada para compor as camadas de base e sub-base (ZIMMER; OMIDO, 2019).

\section{CHAMOTE CERÂMICO}

Os chamotes são um subproduto proveniente de rejeitos de material cerâmico após a queima. No Brasil, uma quantidade considerável de peças cerâmicas para a construção civil são produzidas, como por exemplo telhas, blocos de vedação e blocos estruturais; entretanto, milhões de peças cerâmicas são descartadas pelas indústrias por apresentarem algum tipo de defeito. Assim, visando encontrar um destino adequado a esses materiais Sales (2018) realizou alguns ensaios 
laboratoriais para verificar se o uso de chamotes cerâmicos é adequado para compor as camadas de base e sub-base de pavimentos.

O solo coletado para a realização dos ensaios foi classificado como laterítico, da zona rural de Teresina (PI); os resíduos cerâmicos foram cedidos de uma indústria cerâmica de União (PI). Realizou-se ensaios de Granulometria, Limite de Liquidez, Limite de Plasticidade, Equivalente de Areia, Compactação e Índice de Suporte Califórnia. As misturas de $20 \%$ e $30 \%$ de chamote apresentou resultado adequado para uso em base de pavimento (os valore de CBR variaram de $83 \%$ a $131 \%$ e a expansão foi nula); e os teores de $20 \%, 30 \%$ e $40 \%$ são viáveis para sub-base (CBR variou de $32 \%$ a $98 \%$, a expansão foi nula). Por conseguinte, os resultados da pesquisa mostraram que é possível descartar esses resíduos de forma adequada, de modo a evitar o acúmulo de resíduos nos pátios das indústrias e, ao mesmo tempo reduzir a exploração de jazidas de onde são extraídos os materiais constituintes dessas camadas do pavimento rodoviário (SALES, 2018).

\section{AÇO-BRITA}

O aço-brita é um co-produto gerado durante a produção do aço, é desenvolvido através de umas séries de processos realizados com a escória de aciaria. Macedo (2018), em sua dissertação de mestrado em Geotecnia, verificou a aplicabilidade da mistura desse material em camadas de pavimentos rodoviários (base e sub-base). A pesquisa analisou as misturas de aço-brita com solos tropicais do estado de Minas Gerais. As dosagens foram de 40\%,50\% e 60\%. Após realização dos ensaios necessários (limites de consistência, granulometria, Compactação, CBR, expansão, etc.) constatou-se que o uso das misturas é viável visto que apresentou valores de expansão (variou de 0,12\% a 0,17\%) e CBR (variou de $120 \%$ a 178\%) adequados. 


\section{ESCÓRIA DE ACIARIA}

Costa e Santos (2019) avaliaram, através de ensaios laboratoriais, a possibilidade de se usar a mistura de escória de aciaria com solo local, do município de Porto Nacional (TO), em camadas de pavimentos rodoviários. Os ensaios realizados foram granulometria, limite de liquidez, limite de plasticidade, compactação, expansão e CBR. Realizou-se ensaios com o solo pura, a escória pura e as dosagens solo/escória nas proporções de 15/85 e 30/70. Com os resultados obtidos conclui-se que as duas misturas só sãoindicadas para a camada de sub-base. A mistura com $15 \%$ de escória apresentou CBR de $21,29 \%$ e expansão de 0,0051\%; e a com 30\% de escória o CBR 22,42\% e expansão de $0 \%$.

Em Brasília (DF), Carvalho (2017) realizou ensaios de caracterização granulométrica e de resistência mecânica para investigar o comportamento da mistura solo/escória de aciaria. O solo foi classificado como laterítico e coletado no campus da Universidade Católica de Brasília (UCB), o resíduo foi fornecido diretamente nas dependências da instituição. A dosagem utilizada foi de 30\%solo + 70\%escória. Os resultados foram satisfatórios, obteve-se um CBR de 86,13\% e expansão de 0,09\%, ou seja, conforme norma, a mistura pode ser aplicada em base e sub-base de pavimentos rodoviários. Notou-se que a adição da escória trouxe melhorias ao solo natural.

\section{PÓ DE BRITA}

O pó de brita consiste em um resíduo da sondagem de pedreiras, seu diâmetro máximo é inferior a 4,8 mm. Costa, Sityá e Machado (2019), analisaram a mistura pó de brita com solos a fim de constatar sua viabilidade em fazer parte das camadas de base e sub-base de pavimentos. Para isso realizou-se os ensaios necessários (análise granulométrica, limite de plasticidade, limite de liquidez, compactação, ISC e expansão). Os materiais das misturas foram coletados da cidade de Cacoal (RO). As dosagens solo/pó de brita foram de 85/15 e 75/25. Os resultados da pesquisa RC: 84863

Disponível em: https://www.nucleodoconhecimento.com.br/engenharia-civil/camadas-depavimentos 
mostraram que a adição do pó de brita, na verdade, prejudicou a resistência inicial do solo. Quanto à expansão as misturam mostram-se viáveis para ser utilizadas em quaisquer umas das camadas citadas (porquanto o valor não ultrapassou 0,5\%); todavia, em relação ao CBR, a utilização dessas misturas mostrou-se inviável. O solo natural apresentava CBR de $18 \%$, com as misturas esse valor caiu para $3 \%$ (mistura 85/15) e 1\% (mistura 75/25).

\section{CERÂMICA VERMELHA}

Sem dúvida, os resíduos da indústria da cerâmica vermelha (RCV) são uns dos mais gerados entre os resíduos de construção civil. Com o objetivo de dar uma destinação adequada a esses materias, protegendo o meio ambiente e, ao mesmo tempo, preservando as jazidas de ondem se extrai os materiais que compõe as camadas da pavimentação, Sousa et al. (2019) estudaram a possível substituição dos materiais convencionais pelo RCV. $\mathrm{Na}$ análise realizou-se ensaios com o solo puro, RCV puro e mistura solo/RCV nas proporções 70/30, 50/50 e 30/70. Os materiais foram coletados da Região Metropolitana de do Cariri (RMC); o RCV foi obtido nas áreas de descartes de resíduos de quatro cerâmicas e o solo de uma jazida localizada no município de Juazeiro do Norte. Os ensaios realizados foram granulometria, massa específica dos grãos, limite de liquidez e plasticidade, compactação e CBR.

A expansão para todas as misturas consideradas foi nula. Já com relação ao CBR (que variou conforme a energia de compactação) observou-se que com a adição do RCV os valores melhoraram consideravelmente; a mistura de $50 \%$ de RCV foi a que apresentou o melhor desempenho com CBR máximo de 218,98\% (variou de $100,31 \%$ a 218,98\%); a mistura com $70 \%$ de RCV teve CBR máximo de 200,59\% (variou de 7,84\% a 200,59\%); e a mistura de 30\% de RCV objete CBR máximo de $91,87 \%$ (variou de $21,37 \%$ a $91,87 \%$ ). Portanto, as misturas de $30 \%$ e $50 \%$ de RCV apresentaram os melhores resultados por isso têm aplicações mais nobres, podendo

RC: 84863

Disponível em: https://www.nucleodoconhecimento.com.br/engenharia-civil/camadas-depavimentos 
ser aplicadas até em camadas de base e a mistura de $70 \%$ pode ser aplicada como reforço do subleito, sub-base e base (SOUSA et al., 2019).

\section{CINZA DA CASCA DE ARROZ E CAL}

Bonfante e Carpio (2016) estudaram a viabilidade técnica de estabilizar um solo arenoso com cinza de casca de arroz (CCA) e cal. O solo foi coletado do município de Siderópolis (SC), a cinza foi fornecida pela empresa Cereais Célia, em Meleiro (SC) e a cal foi produzida pela empresa Maxical Ltda, que se localiza na cidade de Almirante Tamandaré (PR). As misturas foram as seguintes: a primeira de $80 \%$ de solo arenoso, $15 \%$ de CCA e $5 \%$ de cal, denominada de $15 \% \mathrm{CCA}+5 \% \mathrm{Cal}$; e a segunda de $75 \%$ de solo arenoso, $15 \%$ de CCA e $10 \%$ de cal, denominada de 15\%CCA+10\%Cal. Os ensaios realizados foram: Análise Granulométrica, Massa específica real, Compactação e Índice de Suporte Califórnia. Quanto ao CBR ambas as misturas apresentaram valores satisfatórios. A mistura $15 \% \mathrm{CCA}+5 \% \mathrm{Cal}$ obteve, em 28 dias, CBR de 114\% (energia normal) e CBR de 84,7\% (energia modificada); a mistura 15\%CCA+10\%Cal, no $28^{\circ}$ dia, obteve CBR de 77,7\% (energia normal) e CBR de 161,4\% (energia modificada). A pesquisa não apresentou resultados a respeito das expansões das misturas.

Semelhante ao trabalho citado anteriormente Sousa e Belchior (2017) desenvolveu uma pesquisa analisando o comportamento desses mesmos materiais. Com os resultados obtidos notou-se que a resistência da mistura solo natural e CCA, no que diz respeito aos parâmetros de CBR e expansão, foi melhorada ao se adicionar cal. Com a ausência de cal a mistura solo/CCA se mostra inviável com relação à expansão. Portanto, conclui-se que o uso de CCA é adequado para fazer parte da constituição de sub-base de pavimentos apenas quando se adiciona certa quantidade de cal à dosagem. 


\section{COMPARAÇÃO ENTRE OS MATERIAIS ALTERNATIVOS GRANULARES}

Através da análise da Tabela 2 nota-se que, a exceção da mistura do trabalho E1, todas as demais usaram uma porcentagem significante materiais alternativos granulares, $60 \%$ e $75 \%$. Em todas o CBR médio encontrado foi satisfatório visto que foram superiores a $80 \%$; os valores de expansão média também não decepcionaram, todas menores que $0,5 \%$ atendendo, assim como o CBR, aos requisitos normativos.

Tabela 2 - Comparação entre os resultados encontrados com solo brita e RCD

\begin{tabular}{|c|c|c|c|c|}
\hline \multirow[t]{2}{*}{ Material } & \multirow[t]{2}{*}{ ID } & \multirow[t]{2}{*}{ Dosagem } & \multicolumn{2}{|l|}{ Resultados } \\
\hline & & & $\begin{array}{l}\text { CBR } \\
\text { médio (\%) }\end{array}$ & $\begin{array}{l}\text { Expansão } \\
\text { média (\%) }\end{array}$ \\
\hline Solo & E1 & $35 \%$ solo $+25 \%$ areia $+40 \%$ brita & 98,8 & 0,042 \\
\hline brita & E2 & $40 \% S L A D^{*}+60 \% B^{*} S^{*}$ & 83,28 & 0,07 \\
\hline \multirow[t]{2}{*}{ RCD } & E4 & $75 \%$ RCD + $25 \%$ solo & 93,63 & 0,09 \\
\hline & E5 & $35 \%$ RCD1 + 40\%RCD2 + 25\%solo & 137,66 & 0,44 \\
\hline
\end{tabular}

Fonte: Elaborado pelo autor. SLAD*: Misturas de granulometria descontínua de solo laterítico com agregado graúdo; $B G S^{*}$. Brita Graduada Simples.

Os trabalhos que utilizaram solo brita foram os únicos que variaram a porcentagem de solo na mistura (35\% e $40 \%)$. A diferença em relação aos valores de resistências encontrados pode ser justificada com o fato de que, embora a quantidade de solo seja semelhante, o trabalho E1 além de solo e brita utilizou também areia, enquanto o segundo usou uma mistura denominada SLAD e $20 \%$ a mais de brita. Com isso, o primeiro obteve um CBR de 18,63\% maior e a expansão $66,67 \%$ menor. 
Já os que analisaram RCD manteve a mesma proporção solo (25\%). Todavia, o trabalho E5 utilizou dois tipos de RCD, com porcentagens distintas. Essa variação de RCD junto com os solos, que possuem propriedades distintas, podem explicar o motivo de se ter encontrados valores tão diferentes sendo que a proporção solo RCD teoricamente é a mesma. O trabalho E5 obteve CBR e expansão muito superiores ao $\mathrm{E} 4$, de respectivamente, $47,02 \%$ e $388,89 \%$.

Como já dito, apesar dessas diferenças nos resultados, toadas as misturas possuem viabilidade para serem empregadas em camadas de base e sub-base de pavimentos.

\section{COMPARAÇÃO ENTRE OS MATERIAIS ALTERNATIVOS FINOS}

A Tabela 3 contém a analogia entre alguns materiais finos escolhidos nesta pesquisa: pó de brita, RCV e CCA. Pode-se notar que nem todas as dosagens obtiveram resultados favoráveis consoante os requisitos normativos.

Tabela 3 - Comparação entre os materiais pó de brita, RCV e CCA

\begin{tabular}{|c|c|c|c|c|}
\hline \multirow[t]{2}{*}{ Material } & \multirow[t]{2}{*}{ ID } & \multirow[t]{2}{*}{ Dosagem } & \multicolumn{2}{|l|}{ Resultados } \\
\hline & & & $\begin{array}{l}\text { CBR médio } \\
(\%)\end{array}$ & $\begin{array}{l}\text { Expansão média } \\
(\%)\end{array}$ \\
\hline \multirow{2}{*}{$\begin{array}{l}\text { Pó de } \\
\text { brita }\end{array}$} & \multirow[t]{2}{*}{ E10 } & $85 \%$ solo + 15\%pó de brita & 3 & 0,3 \\
\hline & & $75 \%$ solo + $25 \%$ pó de brita & 1 & 0,5 \\
\hline \multirow[t]{3}{*}{$\mathrm{RCV}^{*}$} & \multirow[t]{3}{*}{ E11 } & $70 \%$ solo + 30\%RCV & 51,15 & 0 \\
\hline & & $50 \%$ solo + 50\%RCV & 155,53 & 0 \\
\hline & & $30 \%$ solo + 70\%RCV & 80 & 0 \\
\hline \multirow[t]{2}{*}{$\mathrm{CCA}^{*}$} & \multirow[t]{2}{*}{ E12 } & $80 \%$ solo + 15\%CCA + 5\%cal & 99,35 & - \\
\hline & & $75 \%$ solo + 15\%CCA + 10\%cal & 119,55 & - \\
\hline
\end{tabular}

Fonte: Elaborado pelo autor. RCV*: Resíduos da Indústria da Cerâmica Vermelha; CCA*: Cinza de Casca de Arroz.

RC: 84863

Disponível em: https://www.nucleodoconhecimento.com.br/engenharia-civil/camadas-depavimentos 
A primeira análise feita é com base na porcentagem de solo que cada trabalho adotou. Observa-se que geralmente a porcentagem de solo das misturas é bem superior em relação aos trabalhos que usaram materiais alternativos granulares; enquanto os granulares utilizaram dosagem de $60 \%$ e $75 \%$, os finos, na maioria das vezes, salvo o trabalho E11, adotaram dosagens de $75 \%$ a $85 \%$.

Os resultados de CBR obtidos com o trabalho E10 mostram que as proporções de solo e pó de brita adotadas inviabilizam a utilização da mistura em pavimentos, apesar de que com relação à expansão as misturas mostraram-se adequadas. O solo original apresentava resistência de CBR superiores aos encontrados com as misturas propostas, ou seja, a adição prejudicou a resistência. A resistência desse solo poderia ser testada com adição de certa proporção de cal à mistura, pois em outros trabalhos foi verificado que este material contribuiu para a melhora nas propriedades de resistência, como é o caso do trabalho E12.

O trabalho que utilizou a cerâmica vermelha apresentou resultados promissores. Nas misturas adotadas a mais viável foi a que utilizou proporções iguais de solo e RCV (ambos 50\%), o acréscimo ou diminuição da quantidade de solo prejudicou o CBR; a expansão permaneceu nula. A mistura é, portanto, adequada para diversas aplicações.

O trabalho $\mathrm{E} 12$, conquanto não apresentou resultados no que diz respeito à expansão, mostrou potencialidade de ser usada em camadas de pavimento. $O$ aumento na porcentagem de cal de 5\% para 10\% (com a diminuição da quantidade de solo e mantida a de CCA) à mistura significou ganho de resistência (CBR). Esses estudos são relevantes porquanto apresenta a possibilidade de proporcionar uma destinação adequada a um material que é gerado em grande escala pelo agronegócio brasileiro.

Enfim, os três trabalhos que utilizaram materiais alternativos finos e que estão sendo comparados, com exceção do E10, constataram a viabilidade das misturas; o mais

RC: 84863

Disponível em: https://www.nucleodoconhecimento.com.br/engenharia-civil/camadas-depavimentos 
completo foi o E11 que conteve resultados de expansão e CBR; o que considerou pó de brita poderia realizar novos ensaios com a adição de outros materiais com dosagens distintas para verificar se as propriedades de resistência são melhoradas.

\section{CONSIDERAÇÕES FINAIS}

Com base nos resultados obtidos é possível afirmar que o objetivo geral desta pesquisa foi atingido. Ou seja, verificou-se que há vários materiais alternativos que possuem viabilidade para serem empregados em camadas de base e sub-base de pavimentos. Os materiais alternativos estudados podem ser divididos em granulares e finos.

Dos materiais granulares tanto o solo brita quanto o RCD apresentaram resultados satisfatórios no que diz respeito aos parâmetros de CBR e expansão; das misturas analisadas as que se destacaram foram as seguintes: $35 \%$ solo $+25 \%$ areia + $40 \%$ brita e 35\%RCD1 + 40\%RCD2 + 25\%solo, dosagens que obtiveram resultados de CBR de 98,8\% e 137,66\% respectivamente. Já com relação aos materiais finos verificou-se que o pó de brita apresentou resultados insatisfatórios e o trabalho que analisou o comportamento da cinza da casca de arroz não apresentou resultados sobre a expansão; assim, o trabalho que analisou misturas com RCV foi o que apresentou os melhores resultados sendo $50 \%$ solo $+50 \% \mathrm{RCV}$ a melhor mistura, que obteve CBR de 155,53\%.

Nos trabalhos que utilizaram materiais granulares nota-se uma menor porcentagem de solo quando comparado aos trabalhos que usaram materiais finos. Enquanto que nas misturas com materiais granulares a porcentagem de solo variou de $25 \%$ a $40 \%$, as que utilizaram materiais finos a variação foi de $30 \%$ a $85 \%$. Percebe-se também que os materiais finos apresentam menores expansões e que a resistência do trabalho que usou CCA elevou-se à medida que a porcentagem de cal foi aumentada. Desse modo, a cal se mostrou eficiente em teores acima de $5 \% \mathrm{com}$ a finalidade de melhorar os valores de resistência.

RC: 84863

Disponível em: https://www.nucleodoconhecimento.com.br/engenharia-civil/camadas-depavimentos 
Portanto, de maneira geral, os resultados encontrados nos trabalhos foram satisfatórios; a maioria dos materiais mostraram, através dos resultados de parâmetros como CBR e expansão, a viabilidade das misturas. São adequadas para serem utilizadas em camadas de base e sub-base de pavimentos. Isso é relevante, pois proporciona uma destinação adequada a muitos materiais que são gerados em grande escala o que, por conseguinte, contribui para a preservação ambiental.

\section{REFERÊNCIAS}

ARAUJO, W. E. L. Aproveitamento de resíduos da extração de micaxisto em pavimentos flexíveis. 2008. 142p. Dissertação (Mestrado em Engenharia do Meio Ambiente). Escola de Engenharia Civil, Universidade Federal de Goiás, Goiânia, 2008.

BONFANTE, M.; CARPIO, J. A. V. D. Estabilização de um Solo Arenoso com Cinza da Casca de Arroz e Cal para Utilização em Camadas de Pavimento. 2015. 16f. Trabalho de Conclusão de Curso (Graduação em Engenharia Civil) Universidade do Extremo Sul Catarinense (UNESC), Criciúma, 2015.

Brasil, CONFEDERAÇÃO NACIONAL DO TRANSPORTE - CNT. Pesquisa CNT de Rodovias 2019. Brasília: CNT: SEST SENAT, 2019, 238p. Acessado 14 fevereiro de 2021.

Brasil, DEPARTAMENTO NACIONAL DE INFRAESTRUTURA DE TRANSPORTES DNIT. Manual de pavimentação 2006 publicação IPR - 719. Acessado 20 de fevereiro de 2021.

COSTA, A. F. T. H. S.; SITYÁ, L. V.; MACHADO, L. F. M. Análise da Adição de Pó de Brita no Melhoramento de um Solo, com Vistas à Pavimentação. Interfaces Científicas. v.3, n.3, p. 75-86, 219. 
COSTA, C. J. B.; PINTO, I. E. 20ํㅗㄹ RPU - REUNIÃO DE PAVIMENTAÇÃO URBANA, 6, 2017, Florianópolis, SC. Anais... Florianópolis: CentroSul, 2017. 2017, 13p. Contribuição ao Estudo de Misturas de Solo-Brita como Base de Pavimentos Flexíveis na Região de Manaus/AM. 20a RPU - Reunião De Pavimentação Urbana, Florianópolis-SC, 6ª Expo Pavimentação, 13p., 28 a 30 de junho de 2017.

COSTA, S. N.; SANTOS, R. O. G. Utilização da escória de aciaria em combinação com solo para uso em camadas de pavimentação rodoviária. Engineering Sciences, v.8, n.1, p.57-66, 2020.

FRAÇA, F. S. G. Metodologia da Pesquisa Científica: Organização estrutural e os desafios para redigir o trabalho de conclusão. Revista Eletrônica "Diálogos Acadêmicos", $\quad$ no $1, \quad$ p. 72-87, 2015. Disponível em: <http://uniesp.edu.br/sites/_biblioteca/revistas/20170627112856.pdf>. Acesso em 19 de fevereiro de 2021.

GERHARDT, T. E.; SILVEIRA, D. T. Métodos de Pesquisa. 1 ed. Porto Alegre: Editora da UFRGS, $2009 . \quad$ Disponível em: <http://www.ufrgs.br/cursopgdr/downloadsSerie/derad005.pdf>. Acesso em $25 \mathrm{de}$ fevereiro de 2021.

GIL, A. C. Métodos e Técnicas de Pesquisa Social. 6 ed. Editora atlas, 2008. Disponível em:<https://ayanrafael.files.wordpress.com/2011/08/gil-a-c-mc3a9todose-tc3a9cnicas-de-pesquisa-social.pdf>. Acesso em 02 de março de 2021.

\section{MACÊDO, I. S. Estudo da Aplicabilidade de Misturas de Açobrita com Solos} Tropicais Típicos de Minas Gerais em Camadas de Base e Sub-Base de Pavimentos Rodoviários. 2018. 141f. Dissertação (Mestrado em Geotecnia) Departamento de Engenharia Civil e Ambiental, Universidade de Brasília, Brasília, DF, 2018. 
OLIVEIRA, L. M. 20ํㅡㄹ RPU - REUNIÃO DE PAVIMENTAÇÃO URBANA, 6, 2017, Florianópolis, SC. Anais... Florianópolis: CentroSul, 2017. 2017, 12p. Aproveitamento e Aplicação do RCD Derivado da Construção Civil em Camadas de Base e Sub-Base de Pavimentação na Cidade de São Luís - MA. 20a RPU Reunião De Pavimentação Urbana, Florianópolis-SC, 6ª Expo Pavimentação, 12p., 28 a 30 de junho de 2017.

PRODANOV, C. C.; FREITAS, E. C. Metodologia do Trabalho Científico: Métodos e Técnicas da Pesquisa e do trabalho Acadêmioco. 2 ed. Novo Hamburgo-RS: Universidade Feevale, 2013. Disponível em: <http://www.feevale.br/Comum/midias/8807f05a-14d0-4d5b-b1ad-1538f3aef538/Ebook\%20Metodologia\%20do\%20Trabalho\%20Cientifico.pdf>. Acesso em 23 fevereiro de 2021.

SALES, N. S. Análise da Mistura de Chamote Cerâmico com Solo Laterítico para a Utilização nas Camadas de Base e Sub-Base de Pavimentos Rodoviários. 218. 77f. Dissertação (Mestrado em Engenharia de Materiais) Instituto Federal de Educação, Ciência e Tecnologia do Piauí, Teresina, 2018.

SANTOS, J. O.; ARAÚJO, C. B. C.; AYRES, T. M. C. Análise da Utilização de RCD em Obras de Pavimentação na Cidade de Fortaleza. Mix Sustentável, Florianópolis, SC, v.5, n.3, p. 65-72, 219.

SENÇO. W. Manual de Técnicas de Pavimentação. 2 ed. São Paulo: Editora PINI Ltda, 2008.

SOUSA, W. M.; RIBEIRO, A. J. A.; XAVIER, I. W. P.; SANTOS, M. V. Resíduos de Cerâmica Vermelha como um Material Ambientalmente Sustentável para Uso na Pavimentação. Revista Eletrônica de Gestão e Tecnologias Ambientais (GESTA). v.7, n.2, p. 202-2013, 2019. 
SOUZA, J. V.; BELCHIOR, I. R. M.20ํㅡㄹ RPU - REUNIÃO DE PAVIMENTAÇÃO URBANA, 6, 2017, Florianópolis, SC. Anais... Florianópolis: CentroSul, 2017. 2017, 11p. Estabilização de Solo Argiloso com Cinza de Casca de Arroz e Cal. 20a RPU Reunião De Pavimentação Urbana, Florianópolis-SC, 6ª Expo Pavimentação, 11p., 28 a 30 de junho de 2017.

ZAPPE, A. P. S.; CALLAI, N. D.; BRAGATO, G. A.; QUEIROZ, C. L.; MELLO, L. B.; WAYHS, C. A. S. P.; RUVER, C. A. Misturas de Solo Argiloso Laterítico do Noroeste do Rio Grande do Sul e Brita Graduada Simples para Uso em Pavimentos Econômicos. 20aㅗ RPU - Reunião De Pavimentação Urbana, Florianópolis-SC, 6⿳a Expo Pavimentação, 2017, Florianópolis, SC. Anais... Florianópolis: CentroSul, 2017. 2017, 9p., 28 a 30 de junho de 2017.

ZIMMER, A. S.; OMIDO, A. R. Avaliação do Potencial de Uso de Resíduos da Construção Civil como Agregado para Base e Sub-Base de Pavimento Asfáltico.2019. 20f. Trabalho de Conclusão de Curso (Graduação em Engenharia Civil) - Universidade Federal da Grande Dourados (UFGD), Dourados/MS, 2019.

Enviado: Maio, 2021.

Aprovado: Maio, 2021. 